\title{
Cumulative Effect of Precipitation Deficit Preceding Severe Droughts in Southwestern and Southern China
}

\author{
Su-ping Wang, Jin-song Wang, Qiang Zhang, Yi-ping Li, Zhi-lan Wang, and Jing Wang \\ Institute of Arid Meteorology, China Meteorological Administration (CMA), \\ Key Laboratory of Arid Climatic Change and Disaster Reduction of CMA, \\ Key Laboratory of Arid Climatic Change and Disaster Reduction of Gansu Province, Lanzhou 730020, China \\ Correspondence should be addressed to Su-ping Wang; sp_wang07ami@sina.com
}

Received 1 December 2015; Accepted 7 March 2016

Academic Editor: Amit Chakraborty

Copyright (C) 2016 Su-ping Wang et al. This is an open access article distributed under the Creative Commons Attribution License, which permits unrestricted use, distribution, and reproduction in any medium, provided the original work is properly cited.

\begin{abstract}
Timely and accurate monitoring of droughts is important for implementing an effective response and for minimizing economic losses. In this paper, the duration and amount of deficit in precipitation before every severe drought were analyzed for 124 meteorological stations based on the weather data from 1961 to 2012. The results showed that deficit in precipitation over a period as short as three months or even shorter could lead to severe drought and the cumulative timescales of precipitation deficit in southwestern China were longer than those in southern China. The distribution of the critical amount of precipitation deficit showed a clear regional difference. Deficits in the western parts of southwestern China and parts of southern China are above $60 \%$, or even above $80 \%$, higher than the other area ranging between $40 \%$ and $60 \%$. On the whole, the critical amount of the deficit preceding severe droughts for the humid southwestern and southern China was lower than that for the semiarid and semihumid areas. The results offer a sound basis for monitoring and forecasting droughts in southern and southwestern China and for issuing early warnings.
\end{abstract}

\section{Introduction}

Drought is the world's costliest stochastic natural disaster affecting more people than any other natural disaster [1] and has been more frequent in recent years over increasingly larger areas [2]. Whereas severe and frequent droughts were common in northwestern and northern China in the past, southwestern and southern China that used to have abundant precipitation have now begun to experience severe droughts, resulting in enormous economic losses [3-15].

Timely and accurate monitoring of droughts is important for implementing an effective response and for minimizing economic losses [16]. However, previous studies on drought focused mainly on "postdisaster analysis," which is analysis of regional characteristics [3-15] or causes [17-22] of droughts. Forecasting and early warnings of a drought have always been the weak links in drought research. Research on critical factors that lead to droughts and characteristic patterns of weather data that normally precede a drought and the critical values of those factors linked to droughts has been somewhat limited, with adverse impacts on the monitoring, early warnings, and risk assessments of droughts.

Drought is essentially a shortage of water caused by an imbalance in the supply of and the demand for water, usually triggered by a severe and persistent deficit in precipitation $[23,24]$. However, drought is a slow process of accumulation of such deficit, and the severity of drought at a given moment is related not only to the current precipitation but also to the cumulative effect of earlier deficit in precipitation. What is the specific relationship between the duration and the amount of precipitation deficit and the severity of drought? What is the minimum duration of precipitation deficit that may lead to drought in southwestern and southern China? Reliable answers to these questions are a prerequisite to accurate monitoring, early warning, and risk assessment of droughts. Differences in temperature, humidity, and evapotranspiration across regions mean that the same degree of precipitation deficit may result in droughts of varying severity in different regions. In semiarid and semihumid regions, for example, a precipitation deficit of $80 \%-95 \%$ in a month or of $70 \%-80 \%$ 
over three months can lead to severe drought, and a value greater than $95 \%$ in a month or $80 \%$ over three months can lead to extreme drought [25]. In Huaihe river basin, which is at the meeting point of semihumid and humid areas, droughts are severe if precipitation is limited to only $60 \%-70 \%$ of the average and extreme if the deficit exceeds $40 \%$ [26]. Among a few such studies on the critical values of precipitation deficit that can result in drought in southern humid areas is one by Huang et al. [27], who pointed out that, in most regions in southern China, severe droughts are linked to a $40 \%$ deficit in precipitation over a year and about $60 \%-80 \%$ deficit over a quarter. Fan et al. [28] maintain that, in Zhejiang province, a seasonal precipitation deficit of $50 \%$ would result in a severe drought. These results show the regional differences in critical values of drought-causing factors. Therefore, to carry out regional monitoring, forecasting, early warning, and risk assessment of droughts objectively and accurately, it is necessary to identify the characteristics of the occurrence and development of local droughts and choose objective criteria for judging the severity of droughts based on local conditions.

Based on the above analysis, those areas in southwestern and southern China that had faced severe or extreme droughts-as judged by the $K$ drought index-in recent years were selected as research areas. By using weather data from 124 meteorological stations in the selected areas, the following features and values were determined: (1) the cumulative timescales of the precipitation deficit that preceded a severe drought at each station; (2) the amount of deficit (as a negative percentage of precipitation anomaly) that preceded a severe drought at each station. By comparing regional differences in the above features and values, their cumulative effect on droughts was estimated to provide a scientific basis for regional drought forecasting, for early warning, and for preventing such disasters or at least mitigating their impact.

\section{Data and Methods}

2.1. Study Area and Data. The study areas in southwestern (refer to Sichuan, Chongqing, Yunnan, and Guizhou provinces) and southern China (refer to Guangxi and Guangdong provinces) comprise 124 meteorological stations. Nearly all stations experience a subtropical climate; however, northwestern Sichuan and the northernmost part of Yunnan are in the plateau climate zone and the southern parts of Yunnan and Guangdong provinces experience a tropical climate. The elevation ranges from below $400 \mathrm{~m}$ in the southeast to more than $3000 \mathrm{~m}$ in the northwest (Figure 1).

For each station, data spanning the years 1961-2012 were collected for a number of variables including monthly mean temperature, maximum temperature, minimum temperature, precipitation, sunshine hours, average wind speed, and relative humidity. All the data were obtained from the National Meteorological Information Center and meet the stipulated criteria for quality control.

2.2. Methods. The degree of drought severity is expressed with $K$ drought index which has been extensively used in

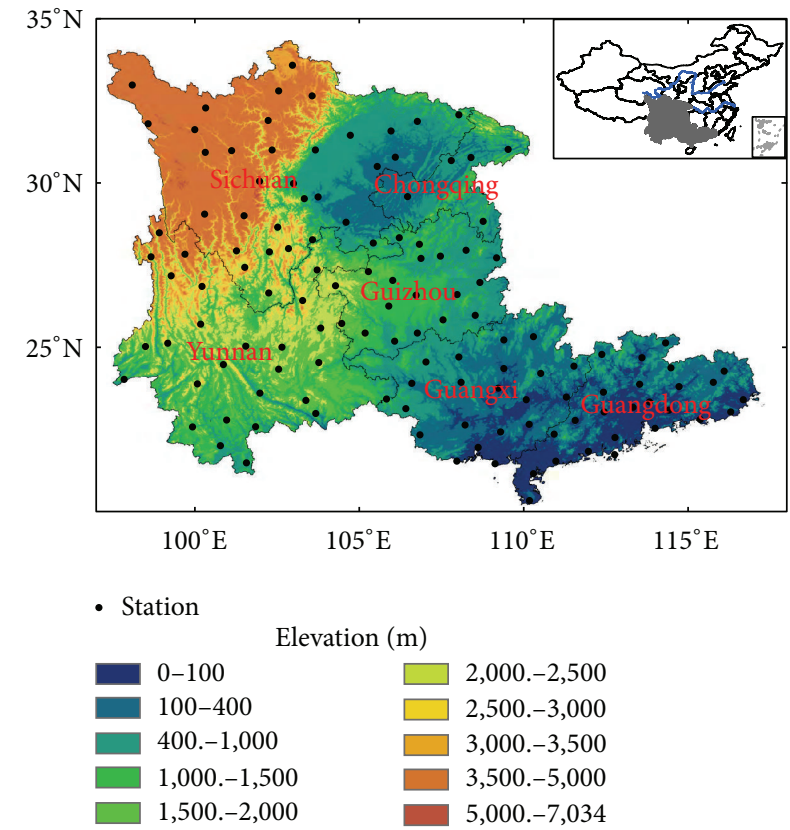

FIGURE 1: The location of southwestern and southern areas in China, the spatial distribution of elevation (unit: $\mathrm{m}$ ), and 124 meteorological stations (dot) in the study area.

southwestern and southern China [29], and Wu et al. [30] showed that the index is a reliable measure of agricultural and hydrological droughts.

The $K$ drought index is defined [31] as follows:

$$
K_{i, j}=\frac{R_{i, j}^{\prime}}{E_{i, j}^{\prime}},
$$

where $K_{i, j}$ is the $K$ drought index and $R_{i, j}^{\prime}$ and $E_{i, j}^{\prime}$ are the relative variability rate of precipitation and reference evapotranspiration, respectively, over the stipulated period, $i$ being the year number and $j$ being the number of the meteorological station.

$R_{i, j}^{\prime}$ is given by the following equation:

$$
R_{i, j}^{\prime}=\frac{R_{i, j}}{R_{p j}}
$$

where $R_{i, j}$ is the precipitation over the stipulated period and $R_{p j}$ is the latest 30-year average of precipitation (the normal value) over the stipulated period.

$E_{i, j}^{\prime}$ is given by the following equation:

$$
E_{i, j}^{\prime}=\frac{E_{i, j}}{E_{p j}}
$$

where $E_{i, j}$ is the reference evapotranspiration for the stipulated period and $E_{p j}$ is the latest 30-year average of evapotranspiration (the normal value) over the stipulated period. The reference evapotranspiration was calculated using the 
Penman-Monteith equation recommended by the FAO in 1998 [32]. The equation is defined as

$$
\begin{aligned}
& \mathrm{ET}_{0} \\
& =\frac{0.408 \Delta\left(R_{n}-G\right)+\gamma(900 /(T+273)) U_{2}\left(e_{s}-e_{a}\right)}{\Delta+\gamma\left(1+0.34 U_{2}\right)},
\end{aligned}
$$

where $\mathrm{ET}_{0}$ is the reference evapotranspiration $\left(\mathrm{mm} \mathrm{day}^{-1}\right)$, $R_{n}$ is the net radiation at the crop surface $\left(\mathrm{MJ} \mathrm{m}^{-2}\right.$ day $\left.^{-1}\right), G$ is the soil heat flux density ( $\left.\mathrm{MJ} \mathrm{m}^{-2} \mathrm{day}^{-1}\right), T$ is the mean daily air temperature at $2 \mathrm{~m}$ height $\left({ }^{\circ} \mathrm{C}\right), U_{2}$ is the wind speed at $2 \mathrm{~m}$ height $\left(\mathrm{m} \mathrm{s}^{-1}\right), e_{s}$ is the saturation vapour pressure $(\mathrm{kPa}), e_{a}$ is the actual vapour pressure $(\mathrm{kPa}), e_{s}-e_{a}$ is the saturation vapour pressure deficit $(\mathrm{kPa}), \Delta$ is the slope of saturation vapour pressure curve at air temperature $T\left(\mathrm{kPa}^{\circ} \mathrm{C}^{-1}\right)$, and $\gamma$ is the psychrometric constant $\left(\mathrm{kPa}^{\circ} \mathrm{C}^{-1}\right)$.

Following the approach proposed by Svoboda et al. [33], each drought was assigned a level from 1 to 5, depending on the severity of the drought (as shown by the $K$ index) according to the percentile method (Table 1). Each category thus indicates the probability (percentile) that a drought of that severity will occur in any given year from 1961 to 2012.

The methods for calculating the cumulative timescales of precipitation deficit and the critical amounts of the cumulative precipitation deficit for each station are as follows. First, the severity of drought at each station is determined according to the monthly $K$ drought index. If the severity of drought is severe or extreme, the drought process is regarded as severe drought. The month in which the drought is rated as above severe (category $\geq 4$ ) for the first time is regarded as the starting month for a severe drought. Second, the cumulative months of negative precipitation anomaly before the occurrence of each severe drought at each station are counted. Additionally, the percentage of severe droughts caused by different durations (number of consecutive months) of precipitation deficit is calculated, and the cumulative timescales of precipitation deficit at each station are ranked in descending order of the above percentage and called the first, the second, the third, the fourth, and so forth, cumulative timescales of precipitation deficit. Third, the precipitation deficit preceding each drought is obtained and paired with the different cumulative timescales. The deficit amounts are divided into four classes in increments of $20 \%$ and the occurring frequency of deficit in each interval is counted. Finally, the deficit at each cumulative timescale for each station is ranked in decreasing order of the above frequency and called the first, the second, the third, the fourth, and so forth, precipitation deficit under each timescale.

\section{Results and Analysis}

3.1. Suitability of the K Index for Monitoring Droughts. The $K$ index has proved its validity as a measure of the severity of drought in the study area [29]. This section chooses the severe drought from the autumn of 2009 to the spring of 2010 and the validity of the $K$ index is further attested by examining the correspondence between the $K$ index and the actual situation.
TABLE 1: Categories of the severity of drought as indicated by the $K$ index.

\begin{tabular}{lcc}
\hline Category & Degree of severity & Percentile chance (\%) \\
\hline 1 & No drought & $>30$ \\
2 & Incipient & 15 to $\leq 30$ \\
3 & Moderate & 5 to $\leq 15$ \\
4 & Severe & 2 to $\leq 5$ \\
5 & Extreme & $\leq 2$ \\
\hline
\end{tabular}

As ascertained from the related literatures $[15,20,34-$ 37], droughts occurred mainly in the Yunnan and Guizhou Plateau area and moderate to severe droughts occurred in eastern Yunnan, western Guangxi, most parts of Guizhou, and eastern and northern Guangdong in September 2009. In October 2009, moderate droughts occurred in most parts of southern China and Yunnan and in southern parts of Guizhou; severe droughts occurred in the northern parts of Guangdong, western parts of Guangxi, and southeastern parts of Yunnan. In November 2009, the northern and eastern parts of Yunnan, southern parts of Sichuan, and western parts of Guizhou and Guangxi experienced severe droughts. In December 2009, most parts of Yunnan, southwestern parts of Guizhou, western parts of Guangxi, and southern parts of Sichuan experienced moderate to severe droughts. In January 2010, the drought in Guangxi was relieved, but the northern parts of Yunnan, southern parts of Sichuan, and western parts of Guizhou suffered severe droughts. In February 2010, Yunnan, Guizhou, Guangxi, and southern parts of Sichuan experienced a drought of more than moderate severity. Meanwhile, the droughts in central and northern parts of Yunnan, most parts of Guizhou, and southern Sichuan were moderate and even severe locally. In March 2010, droughts continued to develop. Eastern parts of Yunnan, northwestern parts of Guangxi, southwestern parts of Guangdong, southern parts of Sichuan, and southwestern parts of Guizhou faced severe droughts and, in some pockets, extreme droughts. In April 2010, multiple spells of precipitation were received in the southwestern drought areas, which mitigated the drought. However, moderate droughts were experienced in Yunnan, Guizhou, and northwestern Guangxi.

The results from monthly monitoring of the $K$ index are shown in Figure 2: the locations and the severity as assessed by the index $K$ closely match the actual condition. The index accurately reflects not only the severity of droughts but also their occurrence, development, mitigation, and relief. For example, in January 2010, Guangxi received 1.8 times the normal precipitation, thus bringing relief to the region. Therefore, the $K$ index can be used to describe the drought situation in the study area accurately.

3.2. Cumulative Timescales of Precipitation Deficit. Figure 3 shows the frequency distribution of cumulative months of precipitation deficit preceding severe droughts: most were due to short-term (seasonal scale) deficits in precipitation, about half of the droughts being due to only a month's deficit. A deficit of 2-3 months accounted for $30 \%$ of the droughts and that caused by deficit over one season is less than $20 \%$. 

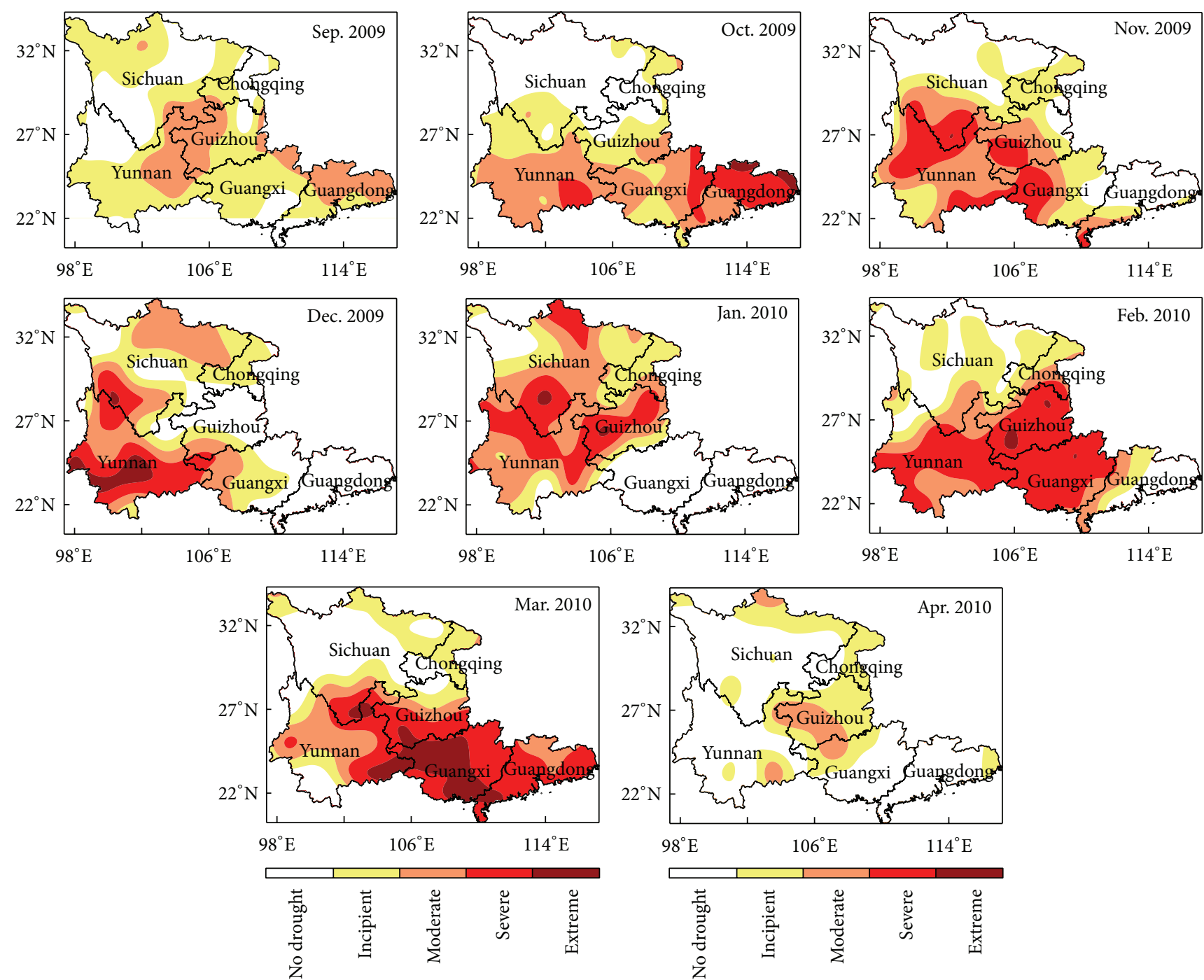

FIGURE 2: Distribution of droughts of varying severity as judged by the $K$ index (Sept. 2009 to Apr. 2010).

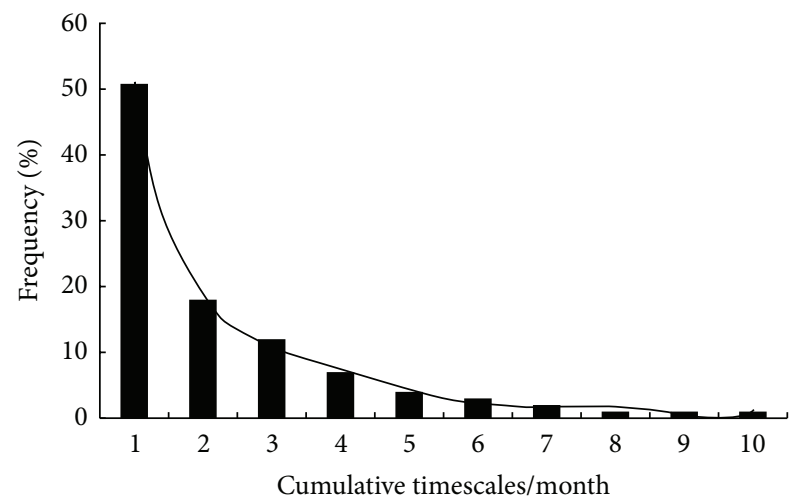

FIGURE 3: Frequency distribution of cumulative timescales.

Figure 4 shows the distribution of the first four cumulative timescales at each meteorological station and also the percentage of droughts accounted for by each timescale. It can be seen that the first timescale of precipitation deficit preceding severe droughts at each station was mainly 1 month. In most parts of south China, Yunnan and Chongqing, and the northeast part of Guizhou, droughts caused by the precipitation deficit at this timescale account for more than $50 \%$ of total droughts. That is, over half of the serious droughts in these areas were due to only a month's deficit in precipitation. In the rest of the study area, 30\%-50\% of the droughts were due to a deficit at a monthly scale (Figure 4(a)).

The second timescale was basically 2 months and accounts for $20 \%-30 \%$ of the total in most part of Sichuan, the western and southeast parts of Guizhou, and the western part of Guangxi and accounts for $10 \%-20 \%$ in the other areas (Figure 4(b)).

The third timescale was mainly 3 months, which accounts for $10 \%-20 \%$ of severe droughts (Figure $4(\mathrm{c})$ ).

The fourth timescale was 4-6 months (Figure $4(\mathrm{~d})$ ). $10 \%-$ $20 \%$ of droughts in West Sichuan Plateau and northern Yunnan are caused by precipitation deficits on this timescale. 


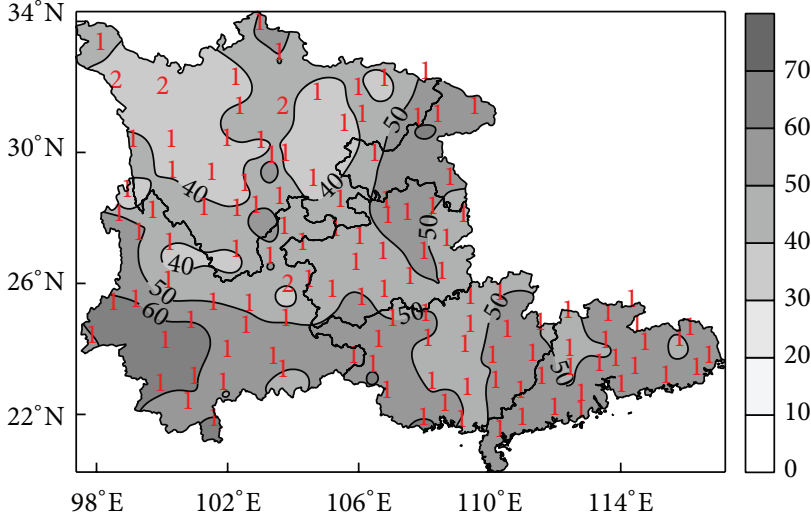

(a)

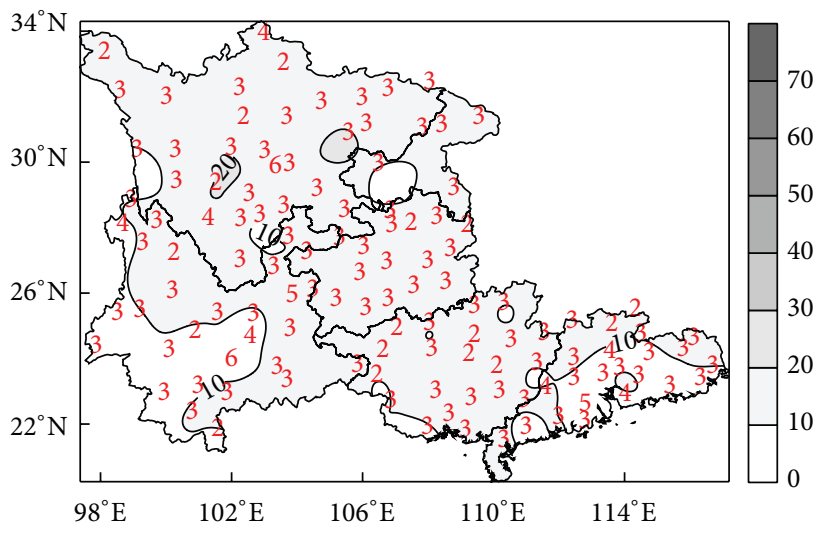

(c)

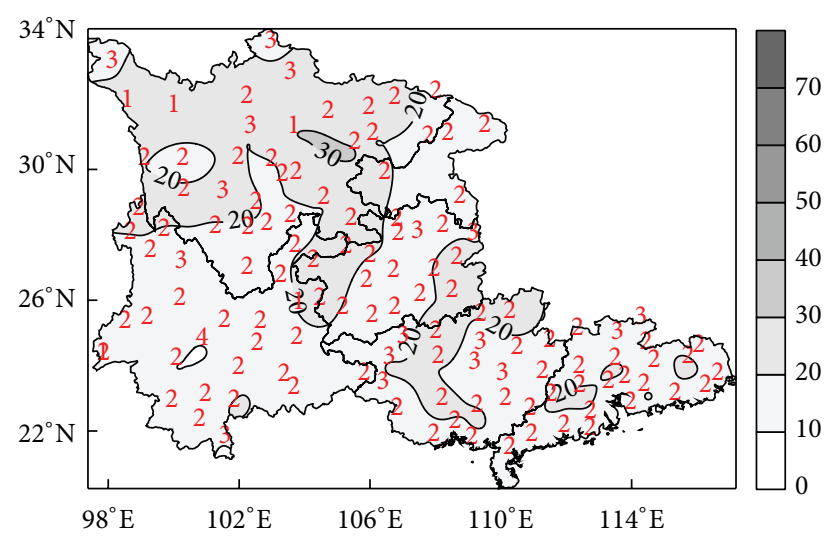

(b)

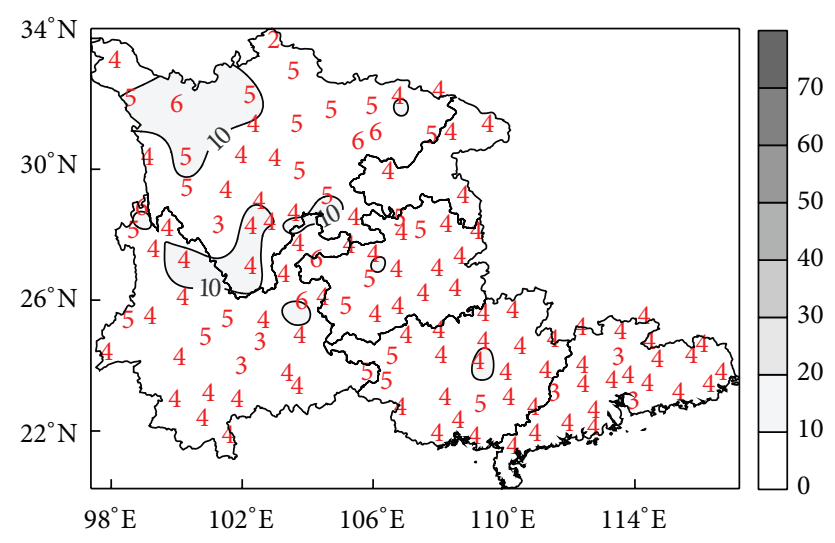

(d)

FIGURE 4: The first 4 cumulative timescales of precipitation deficit (red markers map, unit: month: (a) the first; (b) the second; (c) the third; (d) the fourth) and the proportion of droughts (blank map, unit: \%) due to the deficits of each timescale.

It can be seen that those severe droughts due to extended periods (4-6 months or longer) of precipitation deficit were fewer: most of them are accounted for by deficits lasting up to 3 months. However, droughts due to extended periods of deficit are usually rare, perhaps once in several decades or a century. For example, the severe summer drought in Sichuan and Chongqing in 2006 was preceded by a deficit of 4-5 months in most of the areas (Figure 5). Southwestern China experienced its most severe and sustained drought on record from the autumn of 2009 to the spring of 2010 . The deficit lasted over 4-6 months and even longer in some areas (Figure 6), and the longer the duration, the greater the damage $[20,22,38]$.

The cumulative timescales of precipitation deficit that preceded severe droughts in southwestern China were longer than those in southern China. Severe droughts in southern China were caused mainly by 1-month deficits, whereas in most parts of Sichuan and northern Yunnan, besides the droughts due to 1-month deficit, those due to deficits longer than 2 months are more frequent than other areas.

3.3. Critical Amount of Precipitation Deficit. The analysis in Section 3.2 shows that the duration of precipitation deficit that preceded severe droughts was typically $1-3$ months. The next question is this: On that timescale, what was the amount of deficit that led to severe droughts? The following analysis is therefore confined mainly to the timescale of (a) 1 month and (b) 2-3 months.

3.3.1. Amount of Precipitation Deficit on a Timescale of 1 Month. Figure 7 shows the first four precipitation deficits (as a percentage of deviation from the normal average value for a given station) at one-month timescales of each station and the proportion of droughts (as a percentage of the total number of severe droughts) due to varying degrees of deficit. In Sichuan, Yunnan, and most parts of Guangdong, the more severe droughts occurred when the deficit was more than $80 \%$. And, in most parts of Chongqing, Guizhou, and Guangxi, the deficit that led to severe droughts was smaller: a $60 \%$ deficitor even $40 \%$ in some small pockets. In western parts of southwestern China, about $70 \%$ of the severe droughts were caused by monthly deficits in precipitation exceeding $80 \%$; in other areas, $30 \%-60 \%$ of the severe droughts were caused by deficits of $40 \%-80 \%$. The distribution seen in Figure 7(b) is complementary to that in Figure 7(a): in most parts, $20 \%-40 \%$ of the severe droughts were linked to monthly deficits greater than $60 \%$, whereas, in the West Sichuan Plateau, Chongqing, Guizhou, and northeastern Guangxi, 


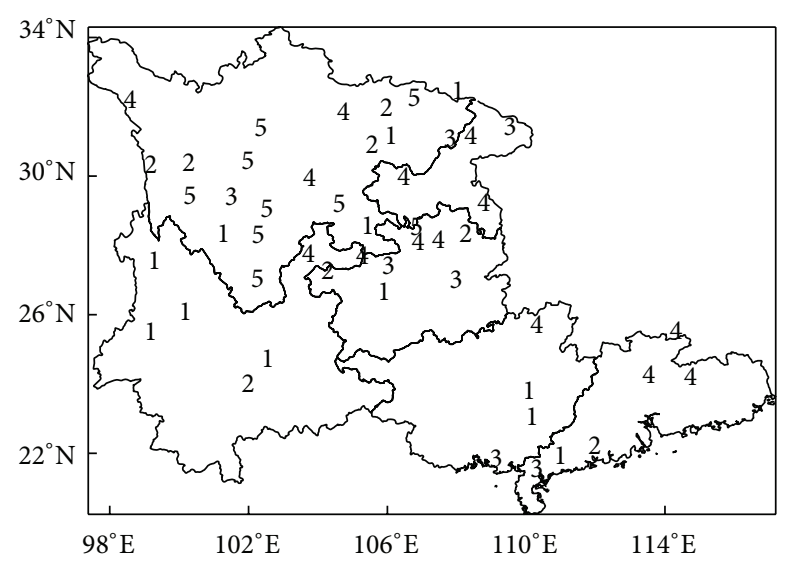

FIGURE 5: Cumulative months of negative precipitation accumulation: June-August 2006.

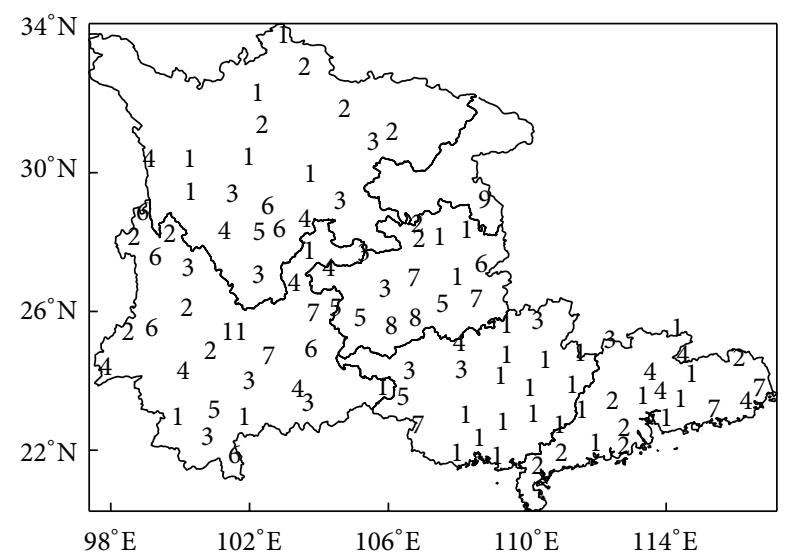

FIgURE 6: Cumulative months of negative precipitation accumulation: October 2009-March 2010.

a much smaller deficit (20\%-40\%) accounted for the same proportion of droughts. The remaining panels of Figure 7 (Figures 7(c) and 7(d)) show that, in eastern Guangxi, 20\% of the severe droughts were due to deficits of $80 \%-100 \%$; in most parts of Yunnan and Guangdong and in central and western Guangxi, about $10 \%$ of the severe droughts were due to deficits of 20\%-60\%; in most parts of Guizhou, about $20 \%$ of the droughts were due to a deficit of $20 \%-60 \%$ and about $10 \%$ were due to a deficit of more than $60 \%$.

As the droughts caused by precipitation deficits around $40 \%-100 \%$ accounted for about $90 \%$ of the total number of severe droughts, each of the amounts of deficit was given a weighting equivalent to the percentage of the total number of droughts due to that category of deficit (Figure 8). It can be seen from Figure 8 that except for some parts of Chongqing, Guizhou, and north-central Guangxi, the monthly precipitation anomaly percentage of $80 \%-100 \%$ covered most of the study area-in other words, when the precipitation deficit reaches $80 \%$, a severe drought is most likely to occur, a pattern consistent with the situation in semihumid and semiarid areas [25]. However, the critical value of precipitation deficit is smaller for southern China and the eastern parts of southwestern China; in these areas, the critical value is $60 \%-80 \%$ or even as low as $40 \%$ in some small pockets.

3.3.2. Cumulative Deficit in the Amount of Precipitation on a Timescale of 2-3 Months. Figure 9 is similar to Figure 8 except that it shows the distribution of precipitation deficit on a timescale of 2 months (Figure 9(a)) and 3 months (Figure 9(b)). It can be seen that the critical value of precipitation deficit lasting for 2 months is lower than that when the deficit lasts for only 1 month. In the western parts of southwestern China and the coastal areas of southern China, the critical value is $60 \%-80 \%$, whereas for other areas it is $40 \%-60 \%$. When the deficit lasts for 3 months (Figure 9(b)), the critical amount was about $40 \%-60 \%$ in most of the areas-far lower than the critical value of $70 \%-80 \%$ for the semihumid and semiarid areas [25]. This indicates that the critical threshold of precipitation deficit leading to severe droughts is lower in southwestern and southern China. In other words, the same amount of deficit that led to only mild droughts in the semihumid and semiarid areas caused severe droughts in southwestern and southern China. Moreover, a precipitation deficit lasting for 2 or 3 months accounted for $20 \%-30 \%$ of the severe droughts in north-central Sichuan but only for 10\%$20 \%$ of them in the remaining areas. This further indicates that the cumulative timescales leading to a severe drought in some parts of Sichuan were longer than that in other areas, and those parts are therefore more likely than other areas to suffer severe droughts caused by long time of negative precipitation accumulation.

3.4. Regional Differences in the Critical Threshold of Precipitation Deficit. To examine regional differences in the critical threshold of precipitation deficit in greater detail, the research area was divided into three subareas, namely, the western parts of southwestern China (Yunnan and Sichuan), the eastern parts of southwestern China (Guizhou and Chongqing), and southern China. The division was based on the characteristics of the spatial distribution at different timescales and under varying amounts of the deficit discussed above. The relationship between the cumulative timescales and the cumulative amount of precipitation deficit was examined by plotting their respective values for each of the three subareas. Another area-the semiarid and semihumid areas-was also introduced in the same graph (Figure 10). The critical value for drought in the eastern parts of southwestern China was the lowest and matched the value for the humid areas, whereas the critical value for the western parts of southwestern China was the highest. The critical value for southern China fell between the above extremes. The differences in the cumulative amounts of the deficit for each area were the largest on the timescale of 1 month or 2 months. In the eastern parts of southwestern China, severe droughts followed a precipitation deficit of about $60 \%$ for 1 month and of about $40 \%$ for 2 months, whereas, for the western parts of southwestern China, the corresponding values were $80 \%$ and $50 \%$. As the timescale was extended, the critical value of precipitation deficit decreased and so did the regional differences. The critical value for each area 


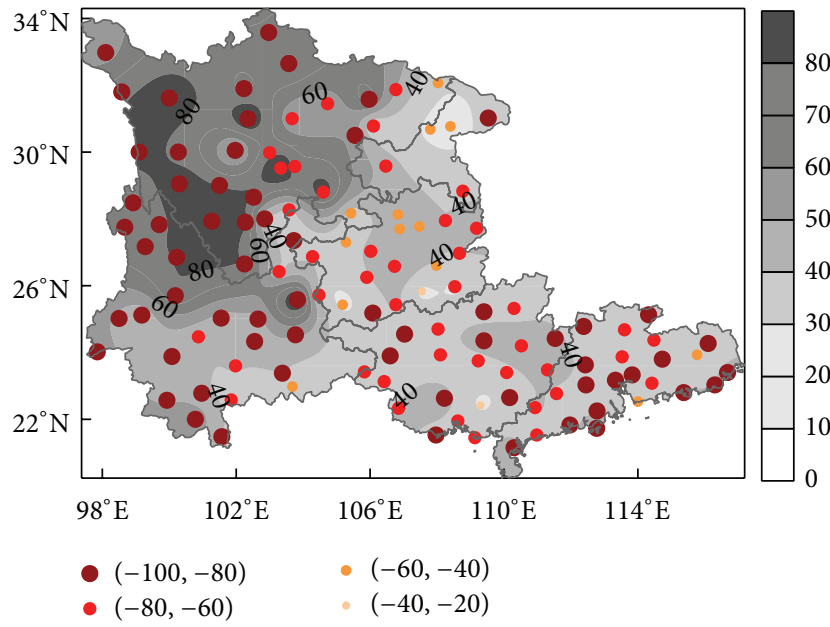

(a)

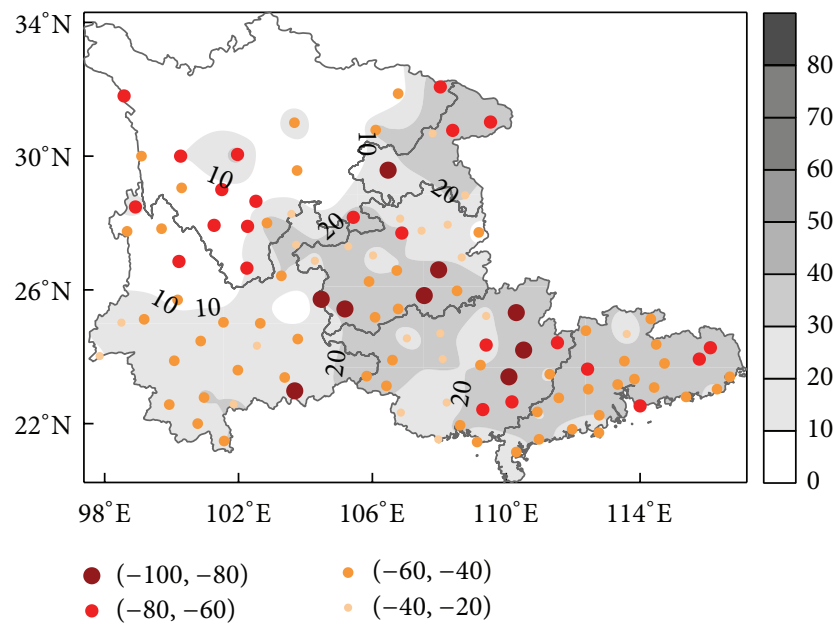

(c)

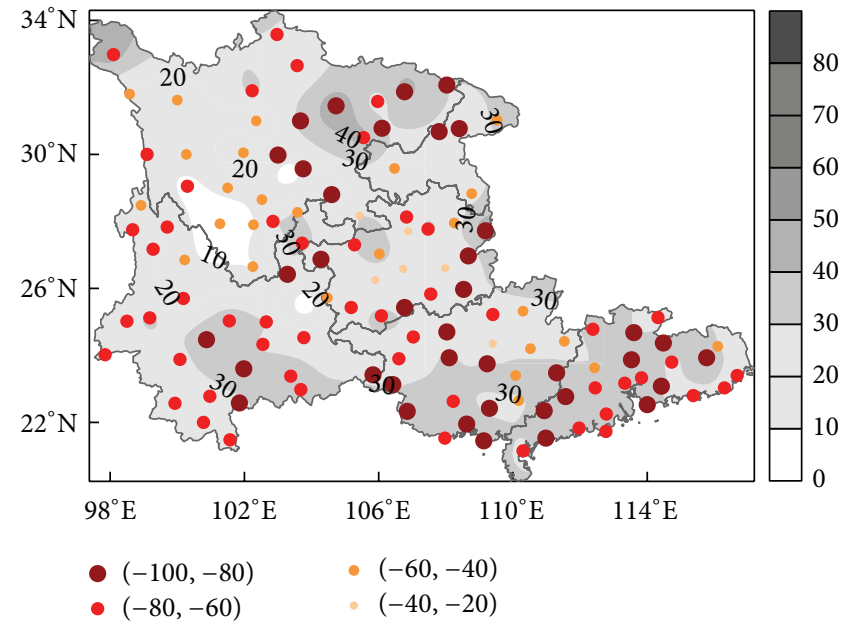

(b)

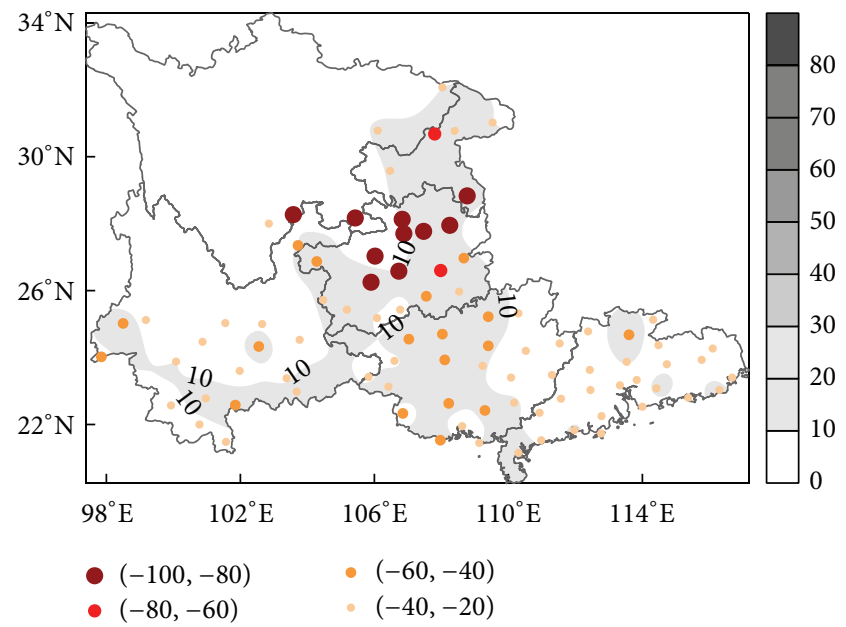

(d)

FIGURE 7: The first 4 precipitation deficits (colored dot, unit: \%: (a) the first; (b) the second; (c) the third; (d) the fourth) under one-month timescale and the proportion of droughts (blank map, unit: \%) due to varying degrees of deficit.

on a timescale of more than 3 months is basically $40 \%$. The critical value for humid areas was the lowest irrespective of the timescale: in humid areas, severe droughts occurred following a smaller precipitation deficit, which is consistent with the research results of Huang et al. [27] and Fan et al. [28]. The average critical values of precipitation deficit in the transitional zone between semiarid and semihumid areas in the western parts of southwestern China are smaller than those in the semihumid and semiarid areas on the timescale of a month or several months (a season). However, spatial distribution of the critical values shows that the critical values for more than half the meteorological stations were close to those in the semihumid and semiarid areas.

\section{Discussion and Conclusion}

(1) Most of the severe droughts in the study area were caused by a precipitation deficit of less than 3 months. The timescale was shorter-of 1 month-in southern China, the southern parts of Yunnan and Chongqing, than that in the remaining areas. However, besides those due to a 1-month timescale, severe droughts due to a deficit of more than 2 months were more frequent in the northern parts of southwestern China than in the remaining areas.

(2) The distribution of the critical values of precipitation deficit showed clear regional differences, especially on the timescales of 1-2 months. Severe droughts occurred in the eastern parts of southwestern China and in north-central Guangxi if the monthly precipitation deficit was $60 \%$ and even $40 \%$ in some small pockets. In other areas, the critical amount of deficit was more than $80 \%$. When the duration was 2 months, the critical value of the amount of deficit was $60 \%-80 \%$ in the western parts of southwestern China and the coastal areas of southern China and $40 \%-60 \%$ in most of the remaining areas. When the duration was 3 months, the critical value was mainly $40 \%-60 \%$. When the duration was more than 3 months, the critical value was generally as low as about $40 \%$. Overall, the critical value of the amount 


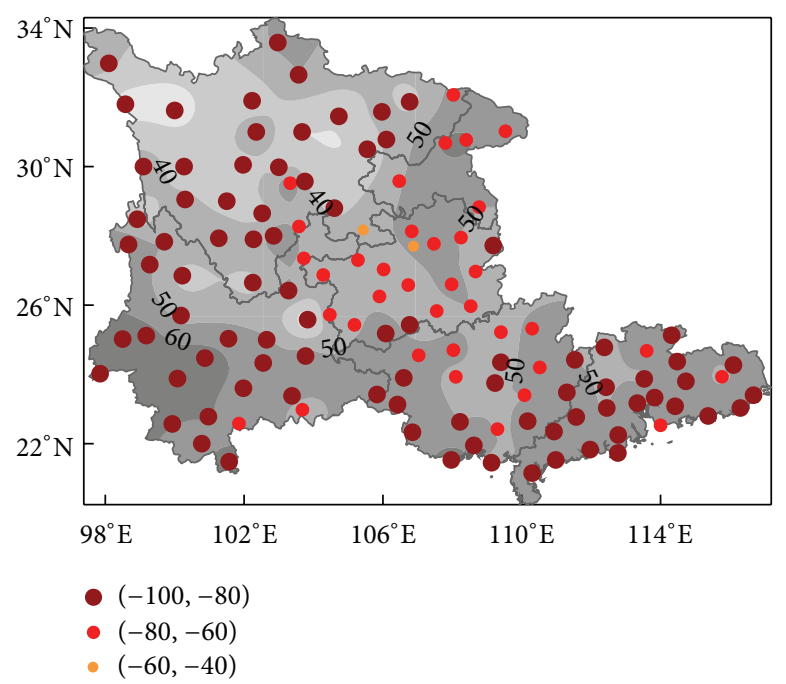

FIGURE 8: Weighting precipitation deficit (colored dot, unit: \%) and the percentage of droughts accounted for by each deficit (blank map, unit: $\%)$. The timescale is 1 month.

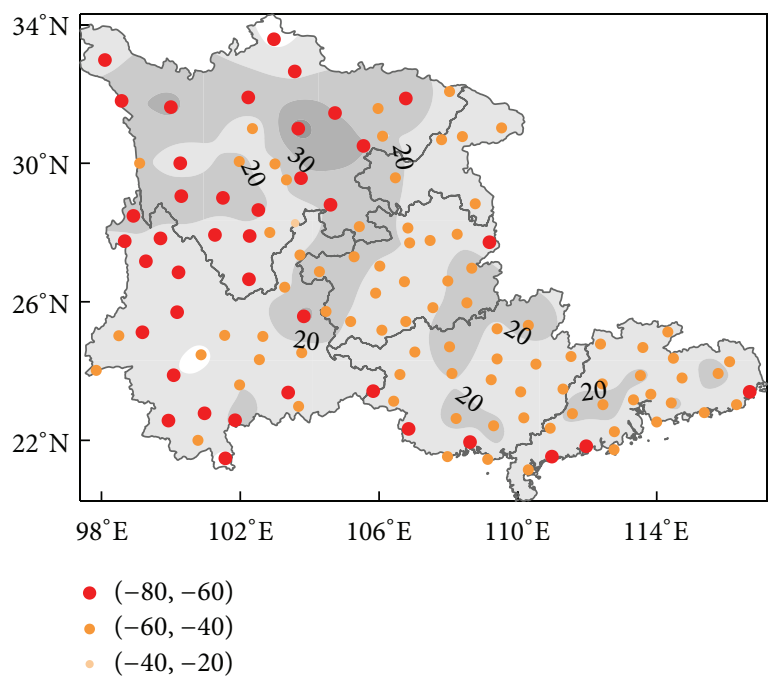

(a)

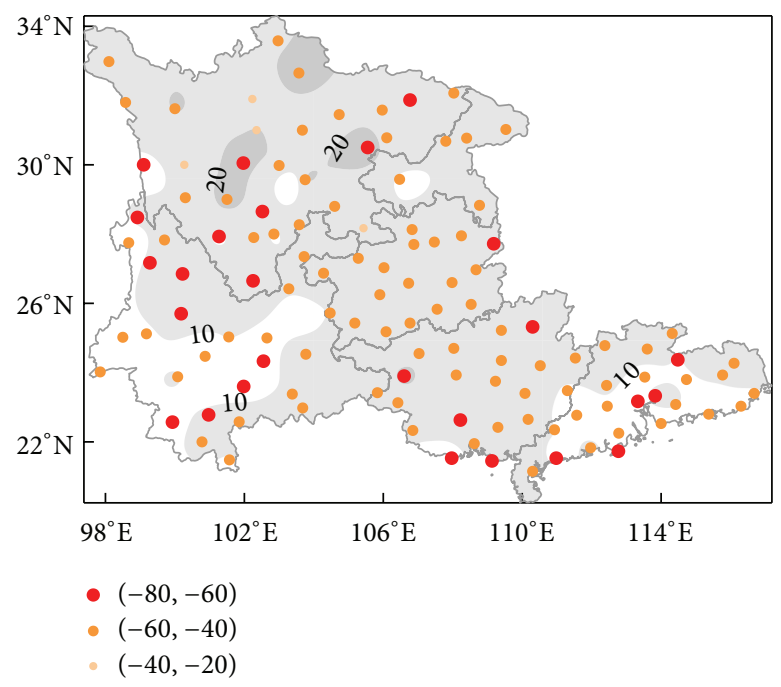

(b)

FIGURE 9: Weighting precipitation deficit (colored dot, unit: \%) and the percentage of droughts accounted for by each deficit (blank map, unit: $\%)$. The timescale is 2 months (a) and 3 months (b).

of precipitation deficit for the eastern parts of southwestern China and most of the areas in southern China was lower than that for the western parts of southwestern China. The longer the timescale, the lower the critical value and the smaller the regional differences.

(3) Regional differences in the critical values of the length of the deficit and its amount were related to the differences in geographic position and climate. The western parts of southwestern China, especially the West Sichuan Plateau and north-central Yunnan, are at a higher elevation and the average temperatures at these higher altitudes are $10-12^{\circ} \mathrm{C}$ lower and evaporation is also $200-400 \mathrm{~mm}$ lower. Therefore, even in the absence of any precipitation deficit, the greater evaporation caused by the higher temperatures can accelerate the development of drought in southern China and in the eastern parts of southwestern China, which is why even small amounts of precipitation deficit in these areas can cause severe droughts in a relatively short time. Zhang et al. [23] also found that the effect of temperature on the occurrence of droughts in southern China was greater than that in southwestern China. In addition, Hou et al. [39] indicated that due to the differences in climate, the timescales that can best reflect the impacts of precipitation deficit and the likelihood of droughts also vary from region to region. Droughts in the western parts of southwestern China, especially in Sichuan and northern Yunnan, were related to precipitation anomalies that lasted longer compared to those in southern China and the eastern parts of southwestern China-a pattern consistent 


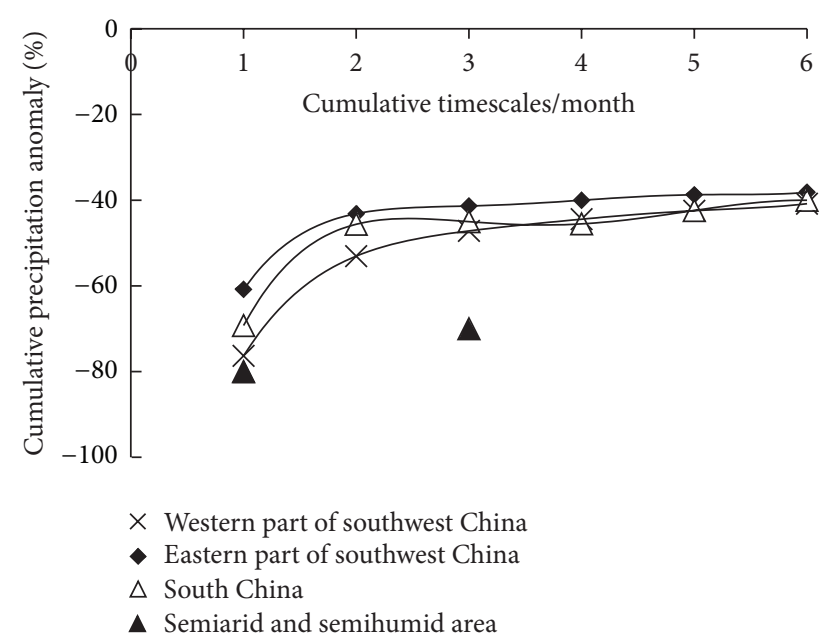

FIGURE 10: Relationship between cumulative timescales and cumulative precipitation deficit in different regions.

with the conclusions of the present study. To conclude, the differences in climate and changes in the climate were the main reasons for the differences in spatial distribution and severity of disasters. We propose to examine such regional differences in greater detail in the future.

\section{Competing Interests}

The authors declare that they have no competing interests.

\section{Acknowledgments}

The authors are grateful for the National Meteorological Information Center of CMA for providing the data used in this study. This research was supported by the National (Key) Basic Research and Development (973) Program of China (Grant no. 2013CB430200).

\section{References}

[1] D. A. Wilhite, "Drought as a natural hazard: concepts and definitions," in Drought: A Global Assessment, D. A. Wilhite, Ed., pp. 3-18, Routledge, 2000.

[2] A. G. Dai, "Drought under global warming: a review," Wiley Interdisciplinary Reviews: Climate Change, vol. 2, pp. 45-65, 2011.

[3] X. K. Zou, P. M. Zhai, and Q. Zhang, "Variations in droughts over China: 1951-2003," Geophysical Research Letters, vol. 32, no. 4, 2005.

[4] A. Wang, D. P. Lettenmaier, and J. Sheffield, "Soil moisture drought in China, 1950-2006," Journal of Climate, vol. 24, no. 13, pp. 3257-3271, 2011.

[5] W. Wang, Y. Zhu, R. G. Xu, and J. T. Liu, "Drought severity change in China during 1961-2012 indicated by SPI and SPEI," Natural Hazards, vol. 75, no. 3, pp. 2437-2451, 2015.

[6] H. P. Chen and J. Q. Sun, "Changes in drought characteristics over china using the standardized precipitation evapotranspiration index," Journal of Climate, vol. 28, no. 13, pp. 5430-5447, 2015.
[7] M. Ye, Z. H. Qian, and Y. P. Wu, "Spatiotemporal evolution of the droughts and floods over China," Acta Physica Sinica, vol. 62, no. 13, Article ID 139203, 2013 (Chinese).

[8] S. P. Wang, C. J. Zhang, Y. H. Li, J. Y. Feng, and J. S. Wang, "Analysis of multi-timescale drought variation based on standardized precipitation index in China during 1960-2011," Journal of Desert Research, vol. 34, no. 3, pp. 827-834, 2014 (Chinese).

[9] Z. F. Ma, J. Liu, S. Q. Zhang, W. X. Chen, and S. Q. Yang, "Observed climate changes in Southwest China during 19612010," Advances in Climate Change Research, vol. 4, no. 1, pp. 30-40, 2014.

[10] W. J. Yu, M. Y. Shao, M. L. Ren, H. J. Zhou, Z. H. Jiang, and D. L. Li, "Analysis on spatial and temporal characteristics drought of Yunnan Province," Acta Ecologica Sinica, vol. 33, no. 6, pp. 317-324, 2013.

[11] L. Wang, W. Chen, W. Zhou, and G. Huang, "Drought in Southwest China: a review," Atmospheric and Oceanic Science Letters, vol. 8, no. 6, pp. 339-344, 2015.

[12] Y. J. Li, F. M. Ren, Y. P. Li, P. L. Wang, and H. M. Yan, "Characteristics of the regional meteorological drought events in Southwest China during 1960-2010," Journal of Meteorological Research, vol. 28, no. 3, pp. 381-392, 2014.

[13] M. J. Zhang, J. Y. He, B. L. Wang et al., "Extreme drought changes in Southwest China from 1960 to 2009," Journal of Geographical Sciences, vol. 23, no. 1, pp. 3-16, 2013.

[14] Y. P. Li, J. S. Wang, and Y. H. Li, "Characteristics of a regional meteorological drought event in Southwestern China during 2009-2010," Journal of Arid Meteorology, vol. 33, no. 4, pp. 537545, 2015 (Chinese).

[15] X. Q. Zhang and Y. Yamaguchi, "Characterization and evaluation of MODIS-derived Drought Severity Index (DSI) for monitoring the 2009/2010 drought over southwestern China," Natural Hazards, vol. 74, no. 3, pp. 2129-2145, 2014.

[16] A. K. Mishra and V. P. Singh, "A review of drought concepts," Journal of Hydrology, vol. 391, no. 1-2, pp. 202-216, 2010.

[17] Y. P. Wu, Y. P. Shen, and B. L. Li, "Possible physical mechanism of water vapor transport over Tarim River Basin," Ecological Complexity, vol. 9, pp. 63-70, 2012.

[18] L. Feng, T. Li, and W. Yu, "Cause of severe droughts in Southwest China during 1951-2010," Climate Dynamics, vol. 43, pp. 20332042, 2014.

[19] J. Yang, D. Gong, W. Wang, M. Hu, and R. Mao, "Extreme drought event of 2009/2010 over southwestern China," Meteorology and Atmospheric Physics, vol. 115, no. 3-4, pp. 173-184, 2012.

[20] E. Lu, Y. Luo, R. Zhang, Q. Wu, and L. Liu, "Regional atmospheric anomalies responsible for the 2009-2010 severe drought in China," Journal of Geophysical Research Atmospheres, vol. 116, no. 21, Article ID D21114, 2011.

[21] W. J. Zhang, F. F. Jin, J. X. Zhao, L. Qi, and H. L. Ren, "The possible influence of a nonconventional El Niño on the severe autumn drought of 2009 in Southwest China," Journal of Climate, vol. 26, no. 21, pp. 8392-8405, 2013.

[22] Y. H. Li, H. M. Xu, and D. Liu, "Features of the extremely severe drought in the east of southwest china and anomalies of atmospheric circulation in summer 2006," Acta Meteorologica Sinica, vol. 25, no. 2, pp. 176-187, 2011.

[23] D. Q. Zhang, L. Zhang, J. Yang, and G. L. Feng, "The impact of temperature and precipitation variation on drought in China in last 50 years," Acta Physica Sinica, vol. 59, no. 1, pp. 655-663, 2010 (Chinese). 
[24] P. M. Zhai and X. K. Zou, "Changes in temperature and precipitation and their impacts on drought in China during 1951-2003," Advances in Climate Change Research, vol. 1, no. 1, pp. 16-18, 2005 (Chinese).

[25] GB/T, "Classification of meteorological drought," Tech. Rep. GB/T20481-2006, Standards Press of China, Beijing, China, 2006 (Chinese).

[26] C. Gao, S. Chen, J. Zhai, Z. Zhang, and Q. Liu, "On threshold of drought and flood disasters in Huaihe River basin," Advances in Water Science, vol. 25, no. 1, pp. 36-44, 2014 (Chinese).

[27] W. H. Huang, Y. Sui, X. G. Yang, S. W. Dai, and M. S. $\mathrm{Li}$, "Characteristics and adaptation of seasonal drought in southern China under the background of climate change. III. Spatiotemporal characteristics of seasonal drought in southern China based on the percentage of precipitation anomalies," Chinese Journal of Applied Ecology, vol. 24, no. 2, pp. 397-406, 2013 (Chinese).

[28] G. F. Fan, C. M. Miao, and Y. D. Mao, "Application of drought indexes to dryness assessment in zhejiang province," Meteorological Monthly, vol. 32, no. 2, pp. 70-74, 2006 (Chinese).

[29] S. P. Wang, J. S. Wang, Q. Zhang, Y. P. Li, and Z. L. Wang, "Applicability evaluation of drought indices in monthly scale drought monitoring in southern China," Plateau Meteorology, vol. 34, no. 6, pp. 1616-1624, 2015 (Chinese).

[30] Z. H. Wu, P. G. Zhan, Z. H. Chen, and Q. W. Fang, "Assessment of the rare drought event occurred in Anshun of Guizhou province by three drought indexes," Journal of Arid Meteorology, vol. 30, no. 1, pp. 315-323, 2012 (Chinese).

[31] J. Wang, S. Wang, Q. Zhang, Y. Li, J. Wang, and J. Zhang, "Characteristics of drought disaster-causing factor anomalies in southwestern and southern China against the background of global warming," Polish Journal of Environmental Studies, vol. 24, no. 5, pp. 2241-2251, 2015.

[32] R. G. Allen, L. S. Pereira, D. Raes, and M. Smith, "Crop evapotranspiration-guidelines for computing crop water requirements," Irrigation and Drainage Paper 56, FAO, Rome, Italy, 1998.

[33] M. Svoboda, D. LeComte, M. Hayes et al., "The drought monitor," Bulletin of the American Meteorological Society, vol. 83, no. 8, pp. 1181-1190, 2002.

[34] L. C. Song, Almanac of China's Meteorological Disaster 2010, Meteorological Press, Beijing, China, 2010, (Chinese).

[35] L. C. Song, Almanac of China's Meteorological Disaster 2011, Meteorological Press, Beijing, China, 2012 (Chinese).

[36] The State Flood Control and Drought Relief Headquarters (SFCDRH) and The Ministry of Water Resources of the People's Republic of China (MWR), China Floods Bulletin 2010, Water and Power Press, Beijing, China, 2011, (Chinese).

[37] Disaster Information Department of National Disaster Reduction Center (NDRC), "Monthly national disaster report (February 2010)," Disaster Reduction in China, vol. 9, pp. 61-64, 2010 (Chinese).

[38] G. Q. Sun, S. L. Wang, Q. Ren, Z. Jin, and Y. P. Wu, "Effects of time delay and space on herbivore dynamics: linking inducible defenses of plants to herbivore outbreak," Scientific Reports, vol. 5, article 11246, 2015.

[39] W. Hou, C. J. Zhang, and G. Gao, "Research on the meteorological drought index based on the hierarchy of climate system," Meteorological Monthly, vol. 38, no. 6, pp. 701-711, 2012 (Chinese). 


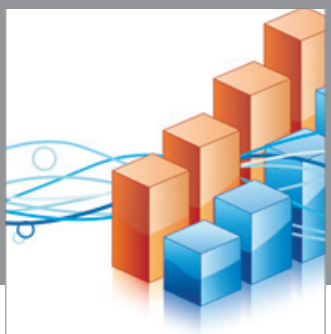

Advances in

Operations Research

vatem alat4

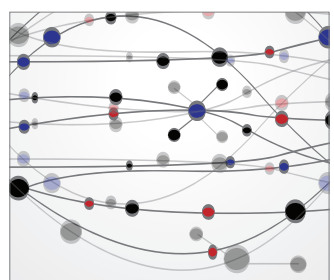

\section{The Scientific} World Journal
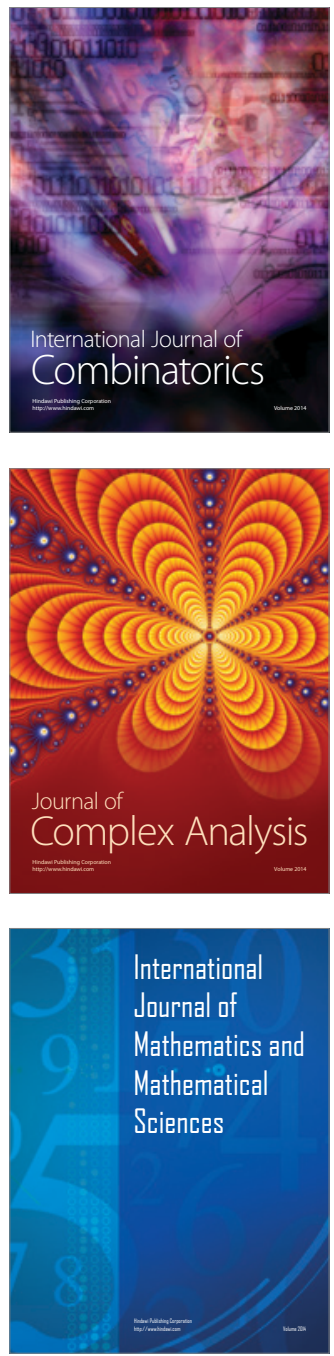
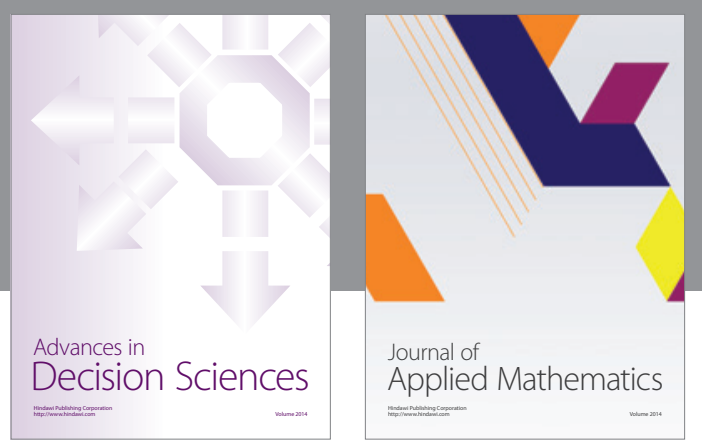

Algebra

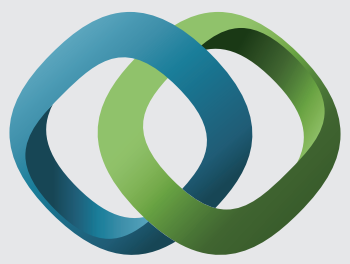

\section{Hindawi}

Submit your manuscripts at

http://www.hindawi.com
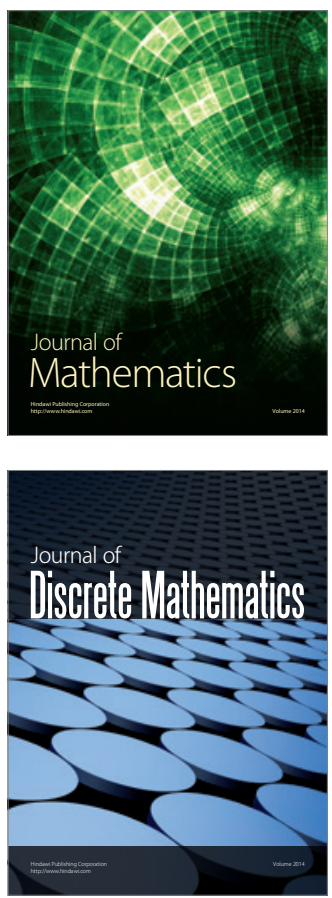

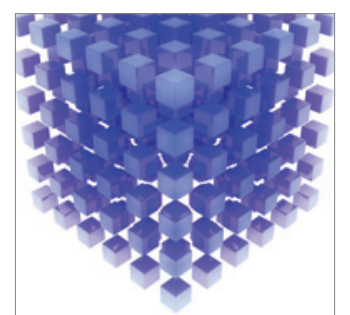

Mathematical Problems in Engineering
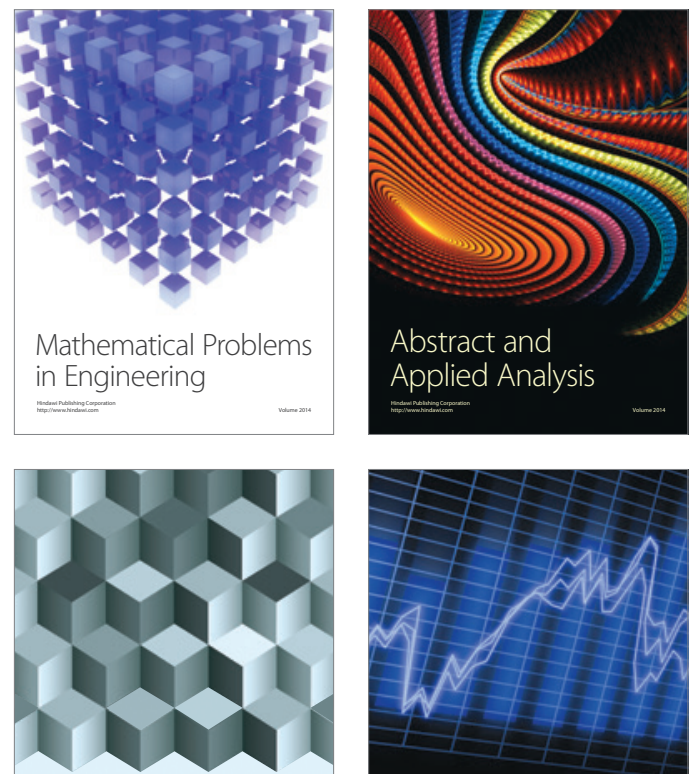

Journal of

Function Spaces

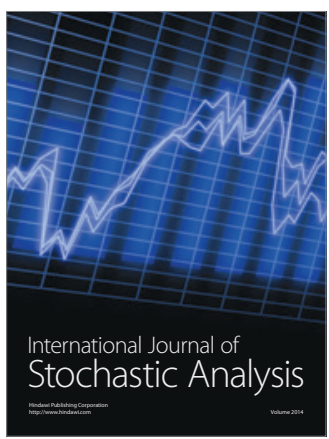

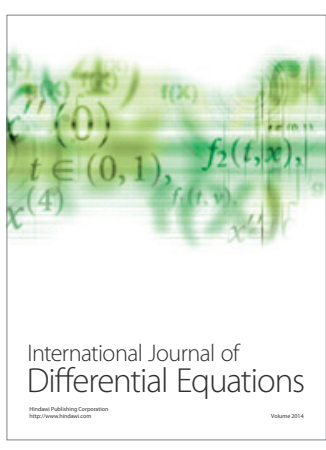
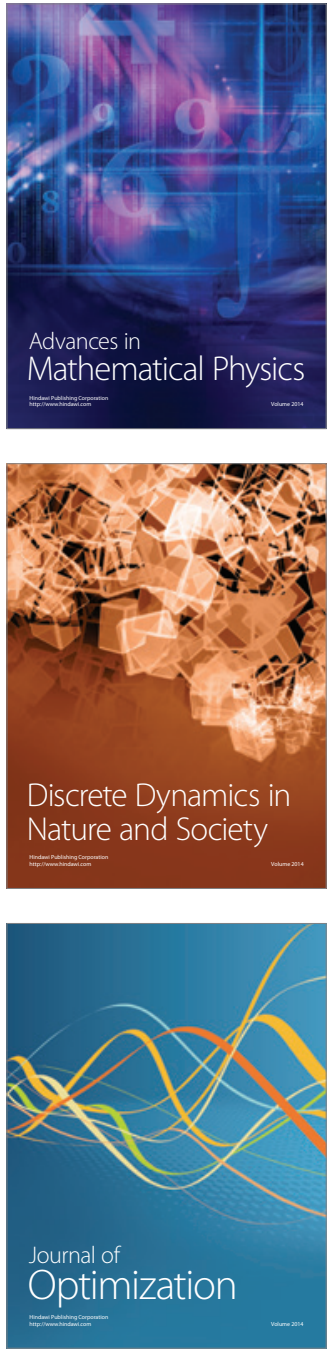